\section{Propagation of Peach Cuttings Using Foam Cubes}

\author{
John D. Avery ${ }^{1}$ and Caula B. Beyl ${ }^{2}$ \\ Department of Plant and Soil Science, Alabama A\&M University, \\ Normal, AL 35762
}

Additional index words. Prunus persica, expanded nodal cutting, hardwood cutting, semihardwood cutting, Horticube, Rootcube

\begin{abstract}
Synthetic polyurethane foam cubes were evaluated as an alternative to conventional peat-based media for rooting of expanded nodal, semihardwood, and hardwood cuttings of peach [Prunus persica (L.) Batsch]. Semihardwood cuttings taken in August had higher rooting percentages in foam cubes than in either of two peat-based media. There were no differences in the number of root initials or lengths of roots among the three media. Semihardwood cuttings of 18 cultivars of peach and nectarine had a mean rooting percentage of $58 \%$ in the peat-perlite-vermiculite medium compared to $77 \%$ for those in foam cubes. There was no difference between rooting percentage or root grade for hardwood cuttings collected in October from either foam cubes or the peat-based medium. Although rooting percentages were lower for expanded nodal cuttings than for semihardwood or hardwood cuttings, there were no differences between the two peat-based media and the foam cubes.
\end{abstract}

Establishing peach plantings on their own roots has been suggested as a way of reducing the initial cost of high-density systems. Several methods of propagation have been used to obtain own-rooted cuttings of the desired peach scion cultivar. In August, Couvillon and Erez (1980a) rooted semihardwood cuttings in vermiculite, or in a volcanic dustpeat-crushed foam plastic medium with $>90 \%$ success in both cases. Robitaille and $\mathrm{Yu}$ (1980) rooted expanded nodal cuttings in May in a medium of 1 soil : 2 peat : 2 perlite (by volume) with $>70 \%$ success. In-field propagation has been used for high-density orchard establishment in several locations; rooting success has varied from $18 \%$ to $82 \%$ with respect to cultivar, date, and location (Erez and Yablowitz, 1981; Krewer and Coston, 1983; Sen and Couvillon, 1983). Since in-field rooting percentages have generally been low, three or more cuttings have been necessary to obtain one tree per site (Couvillon and Erez, 1980b). Soil must be at $12 \mathrm{C}$ or above during the first 40 days for rooting to occur in the field (Erez, 1984), but the locations where temperatures remain consistently above $12 \mathrm{C}$ during the winter are limited.

The media used for greenhouse propagation have varied widely (Couvillon and Erez, 1980a; Erez and Yablowitz, 1981; Lohnes, 1986; Marini, 1983; Okie, 1984; Overcash

\footnotetext{
Received for publication 18 Oct. 1990. This research was supported by U.S. Dept. of Agriculture/Cooperative State Research Service Grant SEA/ CR 95-113. Mention of a trademark or proprietary product does not constitute a guarantee or warranty of the product or its approval to the exclusion of other products that may may also be suitable. The cost of publishing this paper was defrayed in part by the payment of page charges. Under postal regulations, this paper therefore must be hereby marked advertisement solely to indicate this fact. 'Graduate Research Assistant.

${ }^{2}$ Associate Professor.
}

et al., 1983), but generally contain peat in combination with one or more of the following: perlite, vermiculite, or sand. Air-rooting of peach cuttings has also been successful (Coston and Krewer, 1982). Synthetic polyurethane foam cubes have been used with great success in the commercial propagation of poinsettias and geraniums for several years, of root grades from (left to right) 10 to 1 . but there are no reports of their use for rooting of peaches. Foam cubes are priced comparably with conventional rooting media but do not involve the labor-intensive practice of mixing and filling trays or beds. Foam cubes offer the additional advantage that, upon rooting, plants can be transplanted directly to the field with minimal shock. Erez (1984) suggested that heated propagating structures may be necessary for propagation of hardwood cuttings in areas where soil temperatures fall below 12C. Using foam cubes, cuttings could be conveniently rooted in any heated or protected area, such as a greenhouse, garage, or basement, and then transplanted to the field after rooting is obtained. The present work is a comparison of the performance of peach cuttings in foam cubes vs. peat-based media using semihardwood, hardwood, and expanded nodal cuttings.

Cuttings for all of the following studies were collected from peaches and nectarines in three commercial orchards within 30 miles of Huntsville, Ala. Leafy cuttings were placed in plastic bags or coolers to reduce water loss until they were prepared at the greenhouse the same day.

Semihardwood cuttings. In Aug. 1984, semihardwood cuttings of 'Loring' and 'Surecrop' were trimmed to $30 \mathrm{~cm}$ with all but the terminal three to four leaves removed, basally wounded (Couvillon and Erez, 1980a; Sen and Couvillon, 1983), dipped in indolebutyric acid (IBA, $0.3 \%$ in talc), and

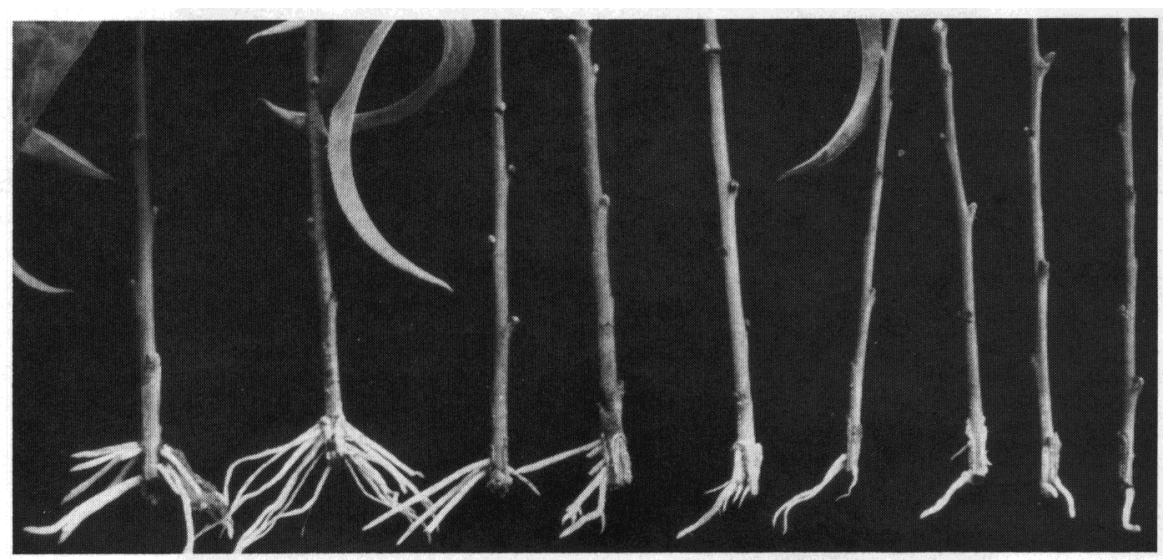

Fig. 1. Semihardwood cuttings of peach 1 month after being placed in Rootcubes illustrating a range

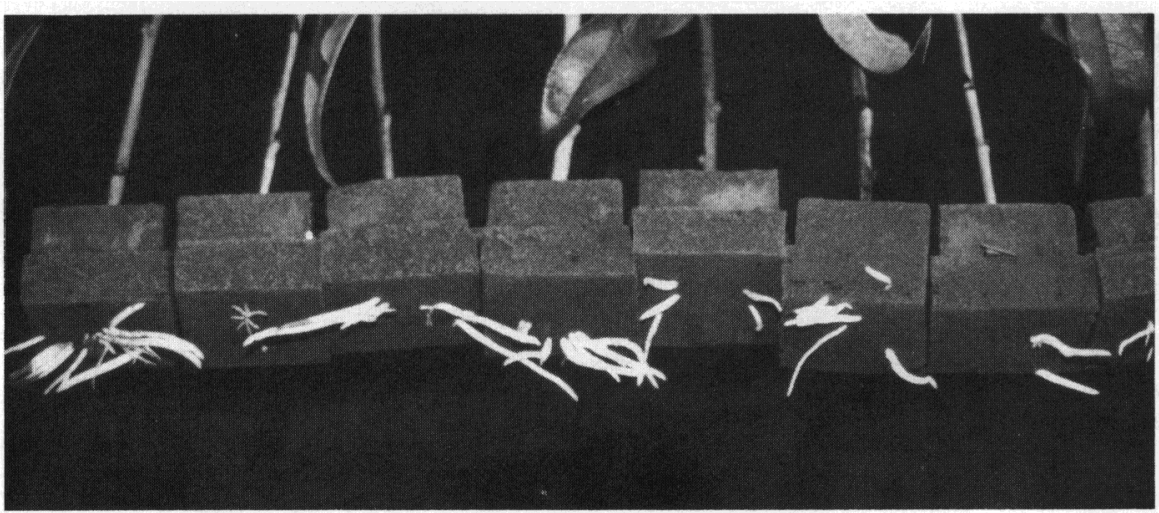

Fig. 2. Penetration of roots of semihardwood cuttings of peach through the base of Rootcubes. 
Table 1. Rooting percentage and root grade of semihardwood cuttings of 'Loring' and 'Surecrop' peach collected in Aug. 1984 in three rooting media.

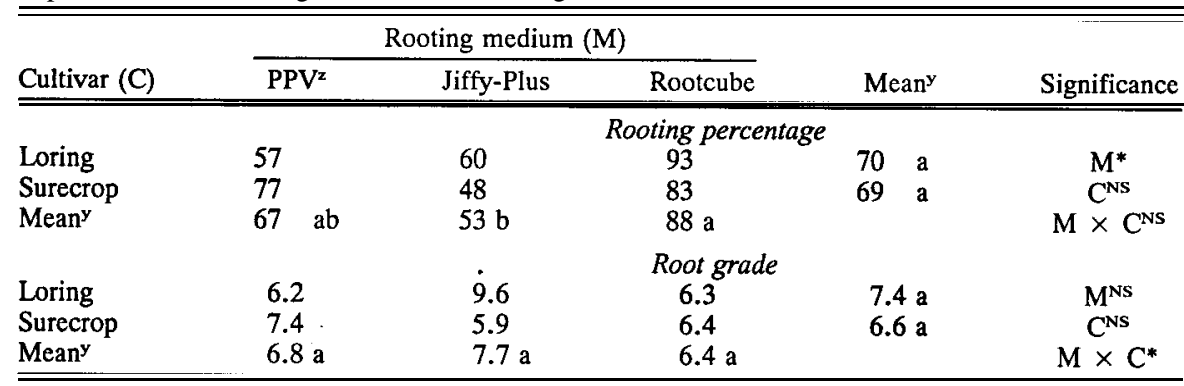

${ }^{1} 1$ Peat : 1 perlite : 1 vermiculite (by volume).

'Mean separation using Duncan's multiple range test, $P=0.05$. Mean represents the average of three replicates of 10 cuttings.

'Extent of rooting rated from $1=$ one or two root initials to $10=$ six or more initials with lateral root development.

${ }_{\text {NS." }}$ Nonsignificant or significant at $P=0.05$, respectively, for effect of $\mathrm{M}, \mathrm{C}$, or the interaction $\mathrm{M}$ $\times \mathrm{C}$.

Table 2. Rooting percentage of semihardwood peach cuttings collected Aug. 1984 as a function of cultivar and rooting medium. ${ }^{2}$

\begin{tabular}{|c|c|c|}
\hline \multirow[b]{2}{*}{ Cultivar } & \multicolumn{2}{|c|}{ Rooting medium ${ }^{y}$} \\
\hline & Rootcubes & PPV $^{x}$ \\
\hline & \multicolumn{2}{|c|}{ Rooting percentage } \\
\hline Nectarines & & \\
\hline Fantasia & 100 & 97 \\
\hline Redgold & 90 & 60 \\
\hline Snoqueen & 80 & 60 \\
\hline \multicolumn{3}{|l|}{ Peaches } \\
\hline Bailey & 73 & 80 \\
\hline Belle of Georgia & 60 & 40 \\
\hline Early Redhaven & 77 & 33 \\
\hline Ferris & 83 & 80 \\
\hline Halehaven & 87 & 73 \\
\hline Jefferson & 73 & 43 \\
\hline Loring & 80 & $\cdots$ \\
\hline Lovell & 73 & 73 \\
\hline Newhaven & 67 & 60 \\
\hline Comp. Redhaven & 100 & 40 \\
\hline Redglobe & 87 & 47 \\
\hline Redhaven & 73 & 50 \\
\hline Redskin & 67 & 43 \\
\hline Siberian $\mathrm{C}$ & 53 & 50 \\
\hline Surecrop & 60 & 60 \\
\hline Mean & $76.7 \pm 13.3$ & $57.7 \pm 19.4$ \\
\hline
\end{tabular}

${ }^{2}$ Since cuttings were collected and rooted at slightly different times, standard error of the mean is used for statistical comparison.

Average of three replicates of 10 cuttings.

1 Peat : 1 perlite : 1 vermiculite (by volume)

then placed in black plastic Universal flats $(53 \times 28 \mathrm{~cm})$ containing one of three media: 1 peat : 1 perlite : 1 vermiculite (PPV) (by volume), Jiffy-Plus (Jiffy Products, Shippegan, Canada), and foam cubes $(3.8 \times 3.8$ $\times 3.8 \mathrm{~cm}$ ) (Oasis Rootcubes; Smithers-Oasis Co., Kent, Ohio). IBA formulations in talc were chosen because of their ease of use and availability to the grower. The best results with talc formulations were found when the cutting surface was kept dry so that only a fine layer of the hormone was deposited on the wounded surface of the cutting. Excessive amounts of the IBA talc formulation on the cut surface caused tissue death. The plastic trays were then placed under an intermittent mist system with mist for $6 \mathrm{sec}$ each 6 min from 6:00 AM to 8:00 PM. A randomized complete-block design in the mist bed with factorial treatment arrangement was used. All treatments consisted of three replications of 10 cuttings each. Means were separated using Duncan's multiple range test (Steele and Torrie, 1960). Main effects were cultivar and medium.

After 1 month, the semihardwood cuttings were evaluated for percentage of rooted cuttings and root grade. Root grade was assigned visually on a scale from $1=$ one or two root initials $<1.5 \mathrm{~cm}$ to $10=$ heavy rooting with many initials and laterals $\geq 2.5$ $\mathrm{cm}$ (Fig. 1). Cuttings in Rootcubes rooted better than in either of the two peat-based media (Table 1, Fig. 2). There were no differences for root grade among the three media, but there was a significant cultivar $\mathrm{x}$ medium interaction for root grade (Table 1). In a separate study conducted at the same time using the same experimental procedure, design, replications, and cuttings per replication, 18 peach and nectarine cultivars were surveyed. Rooting percentages varied from $53 \%$ to $100 \%$, with a mean of $77 \%$ for semihardwood cuttings in Rootcubes, and from $33 \%$ to $97 \%$, with a mean of $58 \%$ for those cuttings in PPV (Table 2).

In 1984, rooted semihardwood cuttings planted by the first week in October had $>90 \%$ survival, while cuttings planted in late October did not survive the winter due to heaving of cuttings from several cycles of freezing and thawing.

Expanded nodal cuttings. In Apr. 1985, 2.5-cm-long, expanded nodal cuttings of 'Compact Redhaven', 'Loring', 'Redhaven', and 'Surecrop' peach and 'Sunglo' nectarine were trimmed from shoots, leaving a 2- to 2.5-cm-long hardwood heel (Robitaille and $\mathrm{Yu}, 1980$ ), dipped in $0.1 \%$ IBA, inserted in the test media, and placed under intermittent mist in PPV, Rootcubes, or Hortcubes (Smithers-Oasis Co.). Rootcubes and Hortcubes are made of inert phenolic resins, but Rootcubes also contain $50 \mathrm{ppm}$ of a $1 \mathrm{~N}-1 \mathrm{P}$ $1 \mathrm{~K}$ starter fertilizer and a cation-exchange clay (B. Waltz, personal communication). All treatments consisted of three replications, 10 cuttings per replication. Generally, rooting percentages (Table 3 ) were lower for expanded nodal cuttings than for rooting per- centages reported in the studies with other types of cuttings (Table 1). There were no significant differences with respect to rooting percentage or root grade among the three media. The response of individual cultivars averaged over the three media ranged from $4.4 \%$ to $54 \%$. 'Redhaven' and 'Sunglo' rooted better in Rootcubes or Hortcubes than in PPV, but 'Loring' had just the opposite response. Root grade was not affected by the medium or by cultivar (range 4.8-8.4). A second parallel study performed in May 1985 with 15$\mathrm{cm}$ expanding nodes gave similar results (data not shown). There was no significant interaction between cultivar and medium for root grade, but there was for rooting percentage. Expanded nodal cuttings in foam cubes planted in the spring survived well (> 90\%).

Hardwood cuttings. In Oct. 1985, 30-cm hardwood cuttings of 'Loring', 'Redhaven', and 'Sunglo' were dipped in $0.3 \%$ IBA in talc and then placed in PPV or Rootcubes in the greenhouse. The same experimental design was used as in previous experiments, with six replications and 10 cuttings/replicate. There were no differences in rooting percentages or root grade of cuttings between the two media, although root grade for hardwood cuttings was quite low (data not shown). 'Sunglo' nectarine rooted better (97\%) than 'Loring' (72\%) or 'Redhaven' (69\%) peaches. Using the same experimental procedure and design but with three replications, cuttings were taken in Oct. 1984 and Jan. 1985 to determine if time of propagation was an important consideration for rooting hardwood cuttings in Rootcubes. There were no differences in either rooting percentage or root grade for time of propagation (data not shown). Although either Oct. 1984 or Jan. 1985 proved to be equally successful with respect to percentage of cuttings that rooted, cuttings should be taken before chilling is satisfied to allow root development before bud swell; otherwise, rooting percentages will be low. Erez (1984) suggested cuttings be taken 6 weeks ahead of anticipated bud swell. Comparison of results in Jan. 1985 and a repeated study with hardwood cuttings in 1986 support this. Cuttings stuck in mid-Jan. 1985 had high rooting percentages $(70 \%$ to $90 \%)$, with bud swell occurring 6 weeks after being stuck, and were completely leafed out within 5 more weeks; cuttings taken 1 year later, in Jan. 1986, showed bud swell within 2 weeks of being stuck. The cuttings died within 2 more weeks. Cuttings should be placed in cold storage to complete the chilling requirement once rooting has occurred. Hardwood cuttings in foam cubes planted in the spring survived well (>90\%).

Reported success with rooting hardwood cuttings directly in the field (Erez and Yablowitz, 1981; Krewer and Coston, 1983; Sen and Couvillon, 1983) suggested a comparable approach conducted in the research pomology orchard, Alabama A\&M Univ., Normal, on Decatur silty clay loam (Rhodic paleudult) previously amended with $6.72 \mathrm{Mg}$ dolomitic lime/ha and $29.4 \mathrm{~kg} \mathrm{P} / \mathrm{ha}$. In Oct. 1982, 30-cm-long hardwood cuttings of 
Table 3. Rooting percentage for expanded nodal cuttings of peach ${ }^{2}$ collected Apr. 1985 as a function of cultivar and rooting medium.

\begin{tabular}{lcccccc}
\hline \hline & \multicolumn{4}{c}{ Rooting medium (M) } & & \\
\cline { 2 - 5 } Cultivar (C) & PPVy & Rootcube & Hortcube & Mean $^{\mathbf{x}}$ & Significance \\
\hline \hline & & 50 & Rooting percentage & & \\
Sunglo-Nectarine & 37 & 50 & 77 & 54 & $\mathrm{a}$ & M $^{\text {NS }}$ \\
Loring & 50 & 37 & 20 & 36 & $\mathrm{a}$ & $\mathrm{C}^{* * *}$ \\
Redhaven & 27 & 43 & 33 & 34 & $\mathrm{a}$ & $\mathrm{M}^{\times} \times \mathrm{C}^{*}$ \\
Comp Redhaven & 6.7 & 6.7 & 14 & $9.0 \mathrm{~b}$ & \\
Surecrop & 3.3 & 3.3 & 6.7 & $4.4 \mathrm{~b}$ & \\
Mean & $25 \mathrm{a}$ & $28 \mathrm{a}$ & $30 \mathrm{a}$ & & \\
\hline \hline
\end{tabular}

${ }^{7}$ Cutting $2.5 \mathrm{~cm}$ long with hardwood heel.

"1 Peat : 1 perlite : 1 vermiculite (by volume).

'Mean separation using Duncan's multiple range test, $P=0.05$. Mean represents the average of three replicates of 10 cuttings.

Ns.***Nonsignificant or significant at $P=0.001$, respectively, for the effect of $\mathrm{M}, \mathrm{C}$, or the interaction $\mathrm{M} \times \mathrm{C}$.

'Loring', 'Redhaven', 'Compact Redhaven', and 'Sunglo' were basally wounded, dipped for $1 \mathrm{~min}$ in $1 \mathrm{~g} \mathrm{IBA} /$ liter, dissolved in $50 \%$ ethanol, and stuck directly in a prepared nursery bed with a control treatment and three mulch treatments: fresh sawdust, cotton gin trash, and hay. There were 125 cuttings in each cultivar/treatment combination but no replication. In-field rooting even under mulch resulted in poor rooting percentages $(5 \%$ to $30 \%$ ) at this location, most likely due to extreme variations in air and soil temperatures in the 40 days after placement. In Oct. 1983, the experiment was repeated with 25 cuttings in each cultivar/treatment and two replications using the same four cultivars but with a bare-ground control and fresh sawdust and 25.4- $\mu$ m-thick black plastic mulch treatments. Again rooting percentages were poor (8\% to 34\%). In each case, the lowest rooting percentage was obtained with the control (no mulch).

Summary and conclusions. Some of the success of the foam cubes as a medium for rooting cuttings, particularly semihardwood cuttings, may be related to better aeration within the medium relative to the peat-based media. Both foam cubes evaluated are capable of absorbing more than 30 times their weight in water when saturated. When excess water is allowed to drain for 35 to 40 min after being saturated, Rootcubes have $36 \%$ and Hortcubes $55 \%$ free air (B. Waltz, personal communication). In contrast, saturating the PPV medium and allowing it to drain for 40 min resulted in a free air value of only $18 \%$. The porosity of Jiffy Plus, the other peat-based medium evaluated, ranges from $20 \%$ to $30 \%$ (J. Kampen, personal communication).

Foam cubes are a satisfactory medium for the propagation of own-rooted peach trees, giving rooting percentages and root quality similar to conventional peat-based media.

\section{Literature Cited}

Coston, D.C. and G.W. Krewer. 1982. Air rooting of peach cuttings. Combined Proc. Intl. Plant Prop. Soc. 32:414-418.

Couvillon, G.A. and A. Erez. 1980a. Rooting, survival, and development of several peach cultivars propagated from semihardwood cuttings. HortScience 15:41-43.

Couvillon, G.A. and A. Erez. 1980b. Production potential and tree regeneration in a peach meadow orchard in the southeastern U. S. Compact Fruit Tree 15:166-175.

Erez, A. 1984. Improving the rooting of peach hardwood cuttings under field conditions. HortScience 19:245-247.
Erez, A. and Z. Yablowitz. 1981. Rooting of peach hardwood cuttings for the meadow orchard, Scientia Hort. 15:137-144.

Krewer, G.W. and D.C. Coston. 1983. Peach meadow orchard establishment techniques. HortScience 18:582. (Abstr.)

Lohnes, J.P. 1986. Propagation of peaches and nectarines by softwood and semi-hardwood cuttings. Plant Prop. 32:7-10.

Marini, R.P. 1983. Rooting of semihardwood peach cuttings as affected by shoot position and thickness. HortScience 18:718-719.

Okie, W.R. 1984. Rapid multiplication of peach seedlings by herbaceous stem cuttings. HortScience 19:249-251.

Overcash, J.P., K. Hancock, and M. Calindo. 1983. Patio peach trees. Mississippi State Univ. Bul. 915.

Robitaille, H.A. and K.S. Yu. 1980. Rapid multiplication of peach clones from sprouted nodal cuttings. HortScience 15:579-580.

Sen, S.M. and G.A. Couvillon. 1983. Factors affecting survival of "in field" rooted hardwood peach cuttings. HortScience 18:324-325.

Steel, R.G.D. and J.H. Torrie. 1960. Principles and procedures of statistics. McGraw-Hill, New York. p. 109. 